\title{
Informática Aplicada à Educação Básica nas Escolas Públicas: Formação de Educadores de Penedo/AL para o Uso das TDIC
}

\author{
André Almeida Silva ${ }^{1}$, André C. Nunes ${ }^{1}$, Jéssica F. S. Barbosa ${ }^{1}$, Lucas L. de O. \\ Garcia $^{1}$, Luziene S. dos Santos ${ }^{1}$, Nicolas L. B. de Albuquerque ${ }^{1}$, Tenilson de Assis ${ }^{1}$ \\ ${ }^{1}$ Unidade de Ensino de Penedo - Universidade Federal de Alagoas (UFAL) \\ Av. Beira Rio S/N, Centro - 57200-000 - Penedo - AL- Brazil
}

\begin{abstract}
andre.almeida@arapiraca.ufal.br, andreadr1926@hotmail.com, j.fernandabarbosal@gmail.com, garcia.lucas.lima@gmail.com, luzieneseixas@hotmail.com, nicolas.b.albuquerque@gmail.com, tenilsonassis@gmail.com
\end{abstract}

\begin{abstract}
The adoption of information and communication technologies has been growing exponentially and, as teaching tools, are increasingly present in the school environment. However, many educators still do not use these technologies in the teaching process, reducing their possibilities. This article exposes the authors' experience in the extension project 'Use of Technology as a Teaching Tool in Public Schools' developed in the Penedo Teaching Unit of the Federal University of Alagoas, which aimed to train teachers in the use of TDICs. Through the results one can think of alternatives of partnerships between University and the network of basic education, seeking to introduce technologies to make teaching and learning more meaningful, interactive and inclusive.
\end{abstract}

Resumo. A adoção de tecnologias da informação e comunicação vem crescendo exponencialmente e, enquanto ferramentas de ensino, estão cada vez mais presentes no ambiente escolar. Contudo, diversos educadores ainda não a utilizam no processo de ensino, reduzindo suas possibilidades. Este artigo expõe a experiência dos autores no projeto de extensão 'Utilização de Tecnologia como Ferramenta de Ensino nas Escolas Públicas', desenvolvido pela Unidade de Ensino de Penedo da Universidade Federal de Alagoas, cujo objetivo foi formar professores quanto ao uso das TDIC. Através dos resultados pode-se pensar em alternativas de parcerias entre Universidade e a rede de educação básica, buscando introduzir tecnologias para tornar o ensino e aprendizagem mais significativo, interativo e inclusivo.

\section{Introdução}

Vivemos em um mundo cada vez mais tecnológico, com grande velocidade no compartilhamento de informações e otimização de tarefas que antes eram dissociadas das Tecnologias Digitais da Informação e Comunicação (TDIC). Esta realidade é fortemente vista no campo da Educação, no qual os recursos computacionais fazem-se, 
VII Congresso Brasileiro de Informática na Educação (CBIE 2018)

Anais do XXIV Workshop de Informática na Escola (WIE 2018)

dia a dia, mais presentes no ambiente escolar, fato que vem modificando e incrementando o processo de ensino e aprendizagem.

A educação não pode estar alheia ao novo contexto socioeconômicotecnológico. Neste cenário, a infraestrutura de TI, com base no computador e telefonia móvel ligados à Internet, é a definidora da nova lógica comunicacional. É posto que "se a escola não inclui a Internet na educação das novas gerações, ela está na contramão da história, alheia ao espírito do tempo e, criminosamente, produzindo exclusão social ou exclusão da cibercultura" [Silva 2005, p. 63]. Assim, há fundamental importância na inserção das tecnologias na educação, facilitando o ensino e incluindo socialmente os indivíduos, promovendo ainda uma formação crítica dos alunos através do uso consciente e criativo das ferramentas computacionais [Boulic e Renault 1991; Muller et al. 2016].

É sabido que as escolas públicas da cidade de Penedo/AL dispõem de um mínimo material tecnológico (computadores, projetores e caixas de som), contudo, boa parte desses equipamentos é subutilizada, sobretudo, porque os educadores não possuem afinidade no seu manuseio e/ou têm receio na utilização de TDIC na educação formal. Neste contexto, perde o professor por restringir sua forma de ensino e os estudantes por ficarem à margem das possibilidades diante do uso das tecnologias na educação.

Para que se passe de um ensino padrão e convencional a um apoiado por novas tecnologias, devem ser desenvolvidos projetos de formação que priorizem a inserção das TICs numa perspectiva construtiva e reflexiva da ação docente [Peña s.d.]. Embora sejam pouco vistos na atualidade, esses projetos devem instigar os educadores quanto à importância do uso adequado de tecnologias e benefícios relacionados à vida profissional dos professores e à educação como um todo. Destaca-se que a informática na educação em nada contribuirá no ensino, caso os professores não tenham o preparo suficiente para ministrar as aulas utilizando os recursos de informática [Bona 2010; Orth 2012].

Uma ação do Governo Federal, criada no ano de 1997, foi o PROINFO (Programa Nacional de Informática na Educação) que tem como objetivo promover o uso pedagógico de tecnologias de informática e comunicações na rede pública de ensino. Trabalhando de forma descentralizada, a operacionalização do programa é conduzida pelos estados, que possuem uma coordenação estadual do PROINFO, e pelos municípios. Em síntese, as coordenações buscam articular esforços e ações necessárias para introduzir efetivamente as TDIC nas escolas, sendo efetivados por meio dos Núcleos de Tecnologia Educacional (NTE), dispondo de profissionais e infraestrutura necessária para qualificar os educadores quanto ao uso da Internet no processo educacional [Nascimento 2007].

Mesmo com o referido programa, a realidade da utilização das TDIC na educação pública básica ainda é mínima, uma vez que os professores não têm formação nem conhecimento acerca das possibilidades pedagógicas do uso de tecnologias em sala de aula, alguns sequer sabem manusear equipamentos básicos de informática, os laboratórios e/ou computadores são insuficientes ou sucateados, há problemas ou a inexistência de acesso à Internet, e uma série de outros fatores que impossibilitam a 
VII Congresso Brasileiro de Informática na Educação (CBIE 2018)

Anais do XXIV Workshop de Informática na Escola (WIE 2018)

inserção e consequentes benefícios das tecnologias da informação e comunicação no processo de ensino.

Neste contexto, o projeto de extensão 'Utilização de Tecnologia como Ferramenta de Ensino nas Escolas Públicas' teve como objetivo formar professores da educação básica da cidade de Penedo/AL, indicando o uso de softwares básicos, da Internet e de equipamentos que as escolas públicas já proveem. Assim, pôde-se ver a mudança do, incialmente, observado receio da utilização da tecnologia no ensino, aguçando ideias voltadas à maximização das potencialidades da informática na educação.

\section{Materiais e Métodos}

O projeto de extensão aqui discorrido e alvo de análise foi realizado no segundo semestre do ano de 2017 na Unidade de Ensino de Penedo da UFAL e contou, como equipe executora, com 2 (dois) docentes da referida instituição, na qualidade de orientadores, e 6 (seis) discentes que foram previamente selecionados, na qualidade de colaboradores e executores das ações planejadas.

Inicialmente, buscou-se elaborar um plano formado por etapas, a fim de sistematizar e melhor definir o passo a passo para a obtenção do resultado pretendido. A execução possui 6 (seis) momentos: i) pesquisa de escolas dotadas de recursos audiovisuais; ii) reunião com a direção das escolas, a fim de divulgar e alinhar o projeto; iii) definição data de realização da formação e inscrição dos professores/participantes; iv) orientação dos discentes envolvidos no projeto acerca da forma e conteúdo a ser ministrado; v) realização da formação dos participantes (professores inscritos); e vi) aplicação de questionário para identificar o aprendizado posterior à formação.

Nas três primeiras etapas os membros da equipe tiveram contato com as escolas, verificando quais delas possuíam equipamentos básicos de informática e multimídia. Constatou-se que as 25 (vinte e cinco) escolas públicas pesquisadas possuíam os referidos equipamentos. A seguir, o projeto foi apresentado aos diretores que se mostraram entusiasmados, ficando responsáveis pela divulgação entre os professores para, na próxima etapa, ser definida uma data e formalizar as inscrições dos participantes que responderam a um questionário sobre seus atuais níveis de utilização/familiarização da informática na educação.

Na quarta etapa de execução, com base nas respostas aos questionários, foram traçados conteúdos e técnicas para que a formação obtivesse o resultado pretendido. Para isso, foi desenvolvida uma apostila com os conteúdos básicos a serem ministrados, tomando o cuidado com a linguagem, formatação e didática apresentadas. Ainda fora analisada a metodologia a ser usada na formação, sendo escolhidas aulas teóricopráticas com o uso dos mesmos meios computacionais que os inscritos poderão utilizar em seus trabalhos.

$\mathrm{Na}$ quinta e sexta etapa a efetiva formação ocorreu. Ela foi realizada, presencialmente, no laboratório de informática, dotado de 20 (vinte) computadores e aparelho de projeção com capacidade de reproduzir som, da Universidade Federal de Alagoas durante 4 (quatro) sábados, a fím de não sobrecarregar ou comprometer o 
VII Congresso Brasileiro de Informática na Educação (CBIE 2018)

Anais do XXIV Workshop de Informática na Escola (WIE 2018)

trabalho dos participantes. Houve ainda a indicação de atividades a serem realizadas à distância, complementando as aulas presenciais.

Com o objetivo de mensurar o aprendizado e aferir a assimilação do que estava sendo ensinado, as atividades em sala foram avaliadas pelos executores do projeto e encerram-se com a aplicação do mesmo questionário já respondido antes da formação. Destaca-se que, a partir das respostas, foi possível inferir concepções acerca do resultado do projeto realizado.

\section{Resultados e Discussão}

Após analisar as respostas dos 10 (dez) questionários iniciais dos participantes da formação, foi verificado que a maioria deles sequer possuíam o domínio básico do computador convencional (desktop), ou seja, alguns não sabiam digitar textos, fazer pesquisas na Internet, salvar fotos nem uma série de outros quesitos que os impediam de utilizarem as tecnologias como ferramentas de apoio ao ensino. Sendo assim, a apostila desenvolvida e citada na seção anterior buscou apresentar todo o embasamento inicial, demonstrado de forma ilustrada e intuitiva, para então partir para as possibilidades pedagógicas.

No decorrer das aulas presenciais (Figura 1 e Figura 2), os professores viram a história e evolução dos computadores e conheceram as partes principais e funcionamento básico dessas máquinas. Eles tiveram acesso aos softwares de escritório da Microsoft Office, com ênfase naqueles que são usualmente utilizados: Word (editor de texto), Excel (planilha eletrônica) e PowerPoint (apresentador de slides). No primeiro foi possível indicar e destacar como a exercícios, avaliações e trabalhos podem ser redigidos facilmente, bem como as formas de torná-los mais atrativos com técnicas de edição. No próximo demonstrou-se as possibilidades e facilidades do trabalho de gestão, apoiado com planilhas, dando ênfase à aplicação de fórmulas e funções, bem como ao gerenciamento de notas e outros aspectos. No último software destacou-se como as aulas podem ficar mais fluidas e melhorar a assimilação dos alunos através do uso de slides no projetor multimídia.

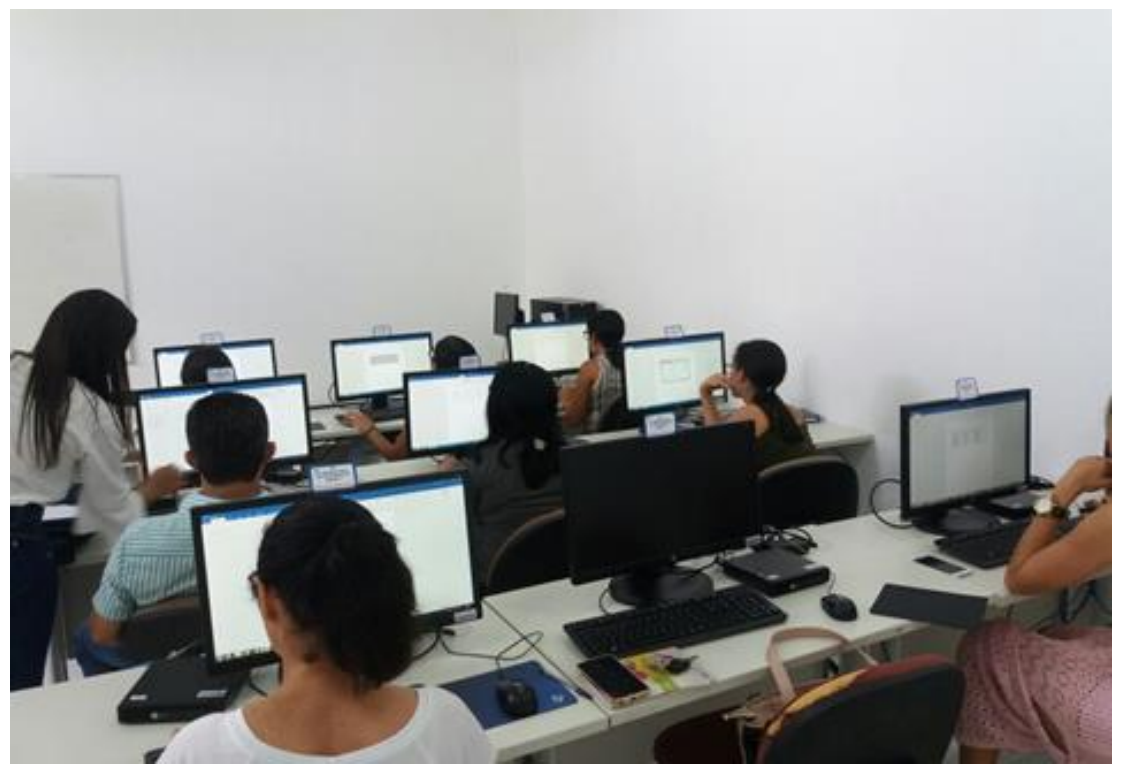

Figura 1. Formação dos participantes do projeto (1) 
VII Congresso Brasileiro de Informática na Educação (CBIE 2018)

Anais do XXIV Workshop de Informática na Escola (WIE 2018)

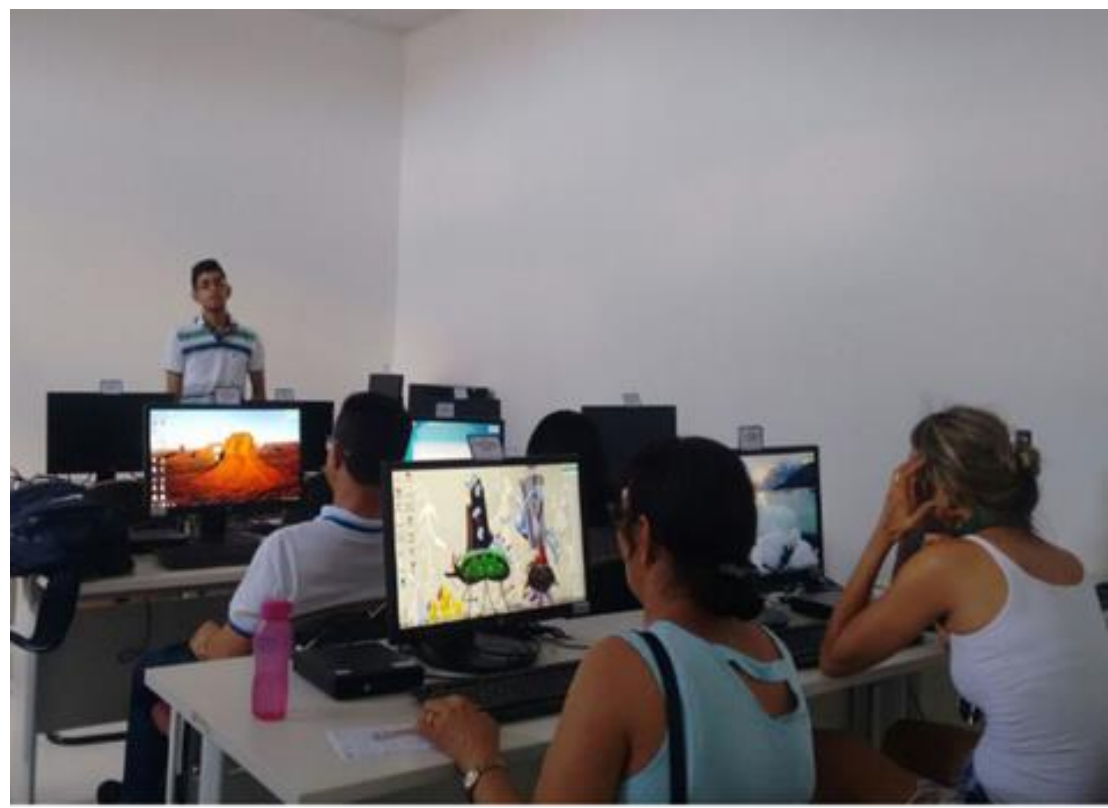

Figura 2. Formação dos participantes do projeto (2)

É importante destacar que hoje os livros didáticos e meios físicos já não vistos como as únicas referências ou fontes de consulta. Com o advento e disseminação da Internet, as formas de adquirir informação e construir conhecimento são fomentadas pelo uso das redes e tecnologias digitais.

É nesta lógica que se reforça a ideia de que a escola precisa repensar suas concepções de ensino/aprendizagem, afastando a verdade, muitas vezes absoluta e inquestionáveis, que apenas o livro e ela própria se configuram como únicas possibilidades de aquisição de conhecimento e de cultura. Deve-se, portanto, partir para outra direção e pensar em outras concepções, nas quais conhecimento, cultura e comunicação se aproximam, observando o processo de ensino e aprendizagem formal diante dos novos parâmetros teórico/conceituais [Mamede-Neves e Duarte 2008].

Foi neste sentido que a formação buscou apresentar a Internet e os referidos softwares numa visão holística, abrangendo não somente o ensino mecânico de programas de computador, mas enfatizando a importância didática e construção de um novo olhar diante do paradigma informacional vigente. É oportuno salientar que as capacidades sensoriais, perceptivas e cognitivas são alteradas e potencializadas ao passo que as novas tecnologias permitem novas formas de se perceber, memorizar, imaginar [Lévy 1999].

É importante mencionar que, mesmo após a formação, muitos dos profissionais ainda encontrarão grande dificuldade para colocar em prática aquilo que se aprendeu durante as aulas do projeto. Uma vez que, quando existentes, os laboratórios são insuficientes e sucateados, é uma tarefa árdua usar TDIC no processo de ensino. Logo, deve-se focar nas estratégias de utilização das tecnologias diante da atuação dos professores em sala de aula, buscando minimizar os problemas de falta de máquinas, tendo em vista que as turmas, em regra, superam os 40 (quarenta) alunos e que as 
VII Congresso Brasileiro de Informática na Educação (CBIE 2018)

Anais do XXIV Workshop de Informática na Escola (WIE 2018)

escolas não foram projetadas inicialmente para destinar um espaço próprio ao uso da informática [Costa e Almeida 2012].

Outro aspecto a ser salientado, diz respeito à resistência por parte de alguns educadores quanto ao uso das TDIC na Educação. Uma das principais justificavas diz respeito à inserção destes professores em um espaço que não lhes é familiar, fato que faz com que eles permaneçam concentrados nas aulas tradicionais e, mesmo quando utilizam as tecnologias, acabam por reproduzir a mesma metodologia, permanecendo com dificuldades para preparar e executar suas aulas [Odorico et al. 2012]. Há ainda a barreira da insegurança, uma vez que se sentem desconfortáveis quanto os alunos dominam as máquinas e as ferramentas melhor do que eles.

Assim, o trabalho buscou formar os educadores quanto à utilização das tecnologias básicas de informática e, ao mesmo tempo, afastar a possível ideia de inferioridade tecnológica perante possíveis "embates" de conhecimento entre esses profissionais e seus alunos. Conforme mencionado, ao final da formação fora aplicado um segundo questionário (idêntico ao inicial) com o propósito de mensurar o aprendizado.

Notou-se, ao final da formação, uma sensível melhora do nível de conhecimento das TDIC estudadas, tanto através da comparação das respostas dadas aos questionários aplicados quanto nas análises feitas pela equipe executora durante a formação em si. Infere-se, pois, que deve haver um pensar constante na adequação dos espaços físicos, na aquisição de equipamentos tecnológicos e na promoção da manutenção, bem como no fornecimento constante de meios para formação, motivação e inovação metodológica dos profissionais da educação [Alves e Souza Junior, 2017].

Em suma, o projeto foi executado de forma muito satisfatória, oportunizando aos professores uma ampliação do olhar voltado à adoção de tecnologias em seus ambientes e cotidianos de ensino.

\section{Conclusão}

O projeto de extensão Utilização de Tecnologia como Ferramenta de Ensino nas Escolas Públicas trouxe grandes e significativos aprendizados para todos os indivíduos envolvidos nele, sejam aqueles que foram alvos diretos da formação, sejam os próprios membros da equipe capacitadora. $\mathrm{O}$ engajamento dos discentes, enquanto executores das ações, nas 6 (seis) etapas supracitadas, iniciadas com a análise das escolas, passando pela confecção da apostila e preparação das aulas, até a aplicação do questionário final foi fundamental para alcançarmos os objetivos pretendidos.

Assim, em relação à participação dos professores destaca-se que a formação, realizada através de aulas teórico-práticas e participativas, proporcionou um incremento no que se refere à atuação profissional dos mesmos, além da inserção deles no mundo tecnológico, oferecendo formas de facilitar tarefas do cotidiano escolar e particular. Ademais, vê-se também o desenvolvimento de uma mentalidade inovadora nos educadores que participaram do projeto, afastando deles o receio no uso das TICs na educação, ao tempo que os tornam verdadeiros difusores das possibilidades pedagógicas das tecnologias diante de outros professores que ainda permanecem avessos a sua utilização. 
VII Congresso Brasileiro de Informática na Educação (CBIE 2018)

Anais do XXIV Workshop de Informática na Escola (WIE 2018)

Soma-se a estes ganhos, a contribuição que o projeto teve na vida pessoal e profissional dos estudantes que colaboraram e fizeram as ações efetivarem-se. Assim, é cumprido o real papel da Universidade, pensando no tripé ensino-pesquisa-extensão, através do contato com a comunidade na qual ela se insere; formando indivíduos capazes atuar como formadores, contribuindo para seu meio social; desenvolvendo capacidades lógicas, cognitivas e uma série de outras nuances que trarão inúmeros benefícios para a formação como um todo.

Pretende-se dar continuidade ao trabalho aqui discutido, investigando mais a fundo as possibilidades pedagógicas das tecnologias já presentes nas escolas da rede pública de ensino de Penedo/AL, pois não adianta formar professores com conhecimentos acerca de TDIC que nem eles nem seus alunos têm acesso. Outro aspecto muito relevante a ser inserido na continuação das pesquisas refere-se à utilização e impacto dos dispositivos digitais móveis no processo de ensino, potencializando cada vez mais as capacidades pedagógicas de aprendizagem.

\section{Referências}

Alves, K. V. A., Souza Junior, A. A. (2017) Um estudo das potencialidades das Tecnologias de Informação e Comunicação, na concepção de alunos e professores de ciências naturais do Município de Macaíba/RN, Anais do XXIII Workshop de Informática na Escola.

Bona, A. S. D. (2010) Portfólio de Matemática: um instrumento de análise do processo de aprendizagem. 2010. Dissertação (Mestrado em Ensino de Matemática) Programa de Pós-Graduação em Ensino de Matemática. Porto Alegre: UFRGS.

Boulic, R. and Renault, O. (1991) “3D Hierarchies for Animation”, In: New Trends in Animation and Visualization, Edited by Nadia Magnenat-Thalmann and Daniel Thalmann, John Wiley \& Sons ltd., England.

Costa, A. L. M., Almeida, F. J. (2012) Condições materiais e a eficácia da informática aplicada à educação: a culpa é do professor?, Anais do XVIII Workshop de Informática na Escola.

Lévy, P. (1999) Cibercultura. São Paulo.

Mamede-Neves, M. A. C., Duarte, R. (2008) "O contexto dos novos recursos tecnológicos de informação e comunicação e a escola", In: Educação e Sociedade, vol. 29, n. 104 - Especial, p. 769-789, out. 2008, Campinas. Disponível em: $<$ http://www.scielo.br/pdf/es/v29n104/a0729104>. Acesso: jun. 2018.

Muller, E. E. R. et al. (2016) A importância dos recursos digitais no ambiente escolar.

Nascimento, J. K. F. (2007) Informática aplicada à educação. Brasília, UnB. Disponível em: $\quad<$ http://portal.mec.gov.br/seb/arquivos/pdf/profunc/infor_aplic_educ.pdf $>$. Acesso: jun. 2018.

Odorico K. E., Nunes D. M., Moreira A., de Oliveira H. M. P., Cardoso A. (2012) Análise do Não Uso do Laboratório de Informática nas Escolas Públicas e Estudo de Caso. Anais do XVIII Workshop de Informática na Escola. 
VII Congresso Brasileiro de Informática na Educação (CBIE 2018)

Anais do XXIV Workshop de Informática na Escola (WIE 2018)

Orth, M. A. (2012) Formação de professores em informática na educação para a educação básica: análises de dissertações e teses. Revista Teoria e Prática da Educação. v. 15, n.1, p. 79-89.

Peña, M. D. J. (s.d) Ambientes de aprendizagem virtual: $\mathrm{O}$ desafio à prática docentes, s.l., s.n.

Silva, M. (2005) "Internet na escola e inclusão", In: Secretaria de Educação a Distância. Integração das tecnologias na educação, Ministério da Educação, Seed, Brasília. 